www.jmscr.igmpublication.org

Impact Factor 5.84

Index Copernicus Value: 71.58

ISSN (e)-2347-176x ISSN (p) 2455-0450

crossref DOI: _https://dx.doi.org/10.18535/jmscr/v5i9.155

Journal Of Medical Science And Clinical Research

\title{
See and Treat Hysteroscopy in Evaluation and Management of Abnormal Uterine Bleeding: Our Experience at a Rural Teaching Hospital of Chhatisgarh
}

\author{
Authors \\ Naik Meena MD, MRCOG ${ }^{1}$, Thaore Swati ${ }^{2}$, Ratnani Rekha ${ }^{3}$ \\ ${ }^{1}$ Asst Professor, Dept of Obgyn, CCM Medical College, Kachandur, Durg, Chhatisgarh \\ ${ }^{2}$ Senior Resident, Dept of Obgyn, CCM Medical College, Kachandur, Durg, Chhatisgarh \\ ${ }^{3}$ Professor and HOD, Dept of Obgyn, CCM Medical College, Kachandur, Durg, Chhatisgarh
}

\begin{abstract}
Abnormal uterine bleeding is a common clinical presentation in gynaecology OPD .it amounts to 35\% of gynae OPD visits and $25 \%$ of gynaecological surgeries and this incidence rises to $65 \%$ in peri and postmenopausal age(1)

Traditionally sonography and D\&C have been standard methods for diagnostic evaluation of AUB and hysterectomy the sole method of treatment. this study outlines the place of hysteroscopy and its role in evaluation and management of $A U B$.

The use of $D \& C$ for evaluation of the uterine cavity in cases of $A U B$ is an inaccurate method for diagnosing most common pathologic conditions associated with menorrhagia like endometrial polyps, Submucous myomas, and focal endometrial abnormalities including adenocarcinoma Hysteroscopy enables see and treat option as the intracavitary pathology can be seen and biopsied and also removed if localized lesion.

Hysterectomy as a treatment option for all cases of AUB is no longer accepted either by patients or by service providers and more and more methods of conservative surgical options or nonsurgical options are being explored for which accurate diagnosis is a must and also malignancy has to be ruled out with considerable surety. hysterectomy is a major surgical procedure with its associated morbidity and cost associated with it and if uterus is not at fault is an overtreatment for those pathologies which can be treated with much simpler and minimally invasive treatment options like hysteroscopic procedures.

Use of hysteroscopy and directed biopsy ensures the recognition as well as removal of these intracavitary lesions. in most cases of endometrial polyps and submucous myomatous polyps there is considerable reduction in bleeding after hysteroscopic removal of these lesions and if no associated endometrial pathology found then hysterectomy can be avoided in these women .thus hysteroscopic management helps in both diagnosis as well as management of a considerable no. Of women with AUB and helps in reducing unnecessary hysterectomies.
\end{abstract}

\section{Aim}

To study the role of "see and treat hysteroscopy" for diagnostic evaluation and management of intrauterine lesions causing abnormal uterine bleeding

\section{Introduction}

Abnormal uterine bleeding is a common clinical presentation in gynaecology OPD .it amounts to $35 \%$ of gynae OPD visits and $25 \%$ of gynaecolo- 
gical surgeries and this incidence rises to $65 \%$ in peri and postmenopausal age $\mathrm{e}^{(1)}$

Traditionally sonography and D\&C have been standard methods for diagnostic evaluation of AUB and hysterectomy the sole method of treatment. this study outlines the place of hysteroscopy and its role in evaluation and management of AUB.

Most common presenting symptoms in women with AUB are menorrhagia in premenopausal women and postmenopausal bleeding. The use of $\mathrm{D} \& \mathrm{C}$ for evaluation of the uterine cavity in cases of AUB is an inaccurate method for diagnosing most common pathologic conditions associated with menorrhagia like endometrial polyps, Submucous myomas, and focal endometrial abnormalities including adenocarcinoma Hysteroscopy enables see and treat option as the intracavitary pathology can be seen and biopsied and also removed if localized lesion.

Hysterectomy as a treatment option for all cases of AUB is no longer accepted either by patients or by service providers and more and more methods of conservative surgical options or nonsurgical options are being explored for which accurate diagnosis is a must and also malignancy has to be ruled out with considerable surety .hysterectomy is a major surgical procedure with its associated morbidity and cost associated with it and if uterus is not at fault is an overtreatment for those pathologies which can be treated with much simpler and minimally invasive treatment options like hysteroscopic procedures .

Use of hysteroscopy and directed biopsy ensures the recognition as well as removal of these intracavitary lesions .in most cases of endometrial polyps and submucous myomatous polyps there is considerable reduction in bleeding after hysteroscopic removal of these lesions and if no associated endometrial pathology found then hysterectomy can be avoided in these women thus hysteroscopic management helps in both diagnosis as well as management of a considerable no. Of women with AUB. and helps in reducing unnecessary hysterectomies.

\section{Materials and Methods}

This is a cross sectional study carried out in department of obstetrics and gynaecology at CCM medical college and hospital, kachandur, durg, chhattisgarh. between $1^{\text {st }}$ January 2015 and $31^{\text {st }}$ December 2016 over a 2 yr period .200 women with abnormal uterine bleeding and intracavitary pathology were included in the study .

All the women with complaints of abnormal uterine bleeding were systematically evaluated with thorough history, examination and cervical cancer screening procedure with pap, VIA and VILI. Sonography was done for all patients and routine investigations in form of $\mathrm{CBC}$, blood group and $\mathrm{RH}$, sickling test. RBS, urine routine microscopy, was done for all patients

All Patients were than subjected to office hysteroscopy and guided biopsy or polypectomy or any other procedure as and when required. It was done in minor OT under local anaesthesia and IV sedation with saline infusion and $4 \mathrm{~mm}$ betochi's office hysteroscope after obtaining informed consent see and treat protocol followed wherever required and wherever appropriate.

Samples of intrauterine lesion and endometrium sent separately in different containers for histopathological study. biopsy reports reviewd for all patients .and results analysed .

Some cases were excluded from study

1. Pregnant women /abortion /missed abortion/ectopic pregnancy

2. Cervical cancer cases

3. Women with PID/STD/vaginitis

4. Women who came with overt malignancy

\section{Observation and Results}

200 patients were included in study with abnormal hysteroscopic findings who had undergone see and treat hysteroscopic procedure.

The age distribution, presenting symptoms and sonographic findings of these 200 patients have been charted here with their hysteroscopic findings and also the procedure done and final histopathological results. 
Table 1 -Age distribution of patients

\begin{tabular}{|l|c|c|}
\hline Age group & Total no & $\%$ \\
\hline $20-29$ yrs & 07 & $3.5 \%$ \\
\hline $30-39 y r s$ & 34 & $17 \%$ \\
\hline $40-49 y r s$ & 122 & $61 \%$ \\
\hline $50-59$ yrs & 32 & $16 \%$ \\
\hline >60yrs & 05 & $2.5 \%$ \\
\hline Total & 200 & \\
\hline
\end{tabular}

The age of patients ranged from 25 to $65 \mathrm{yrs}$ .mean age of patients was 45 yrs. 34 (17\%) patients were in 30-40 yr age group and 122 $(61 \%)$ in $40-50 \mathrm{yrs}$ while $32(16 \%)$ patients were in 50-60 yrs age group, 7(3.5\%) patients were below $30 \mathrm{yrs}$ and $5(2.5 \%)$ patients were above $60 \mathrm{yrs}$. Thus majority of patients ie 154 (77\%) were in peri menopausal and immediate postmenopausal age group (40-60 yrs)

Table 2: distribution of patients according to presenting symptoms

\begin{tabular}{|l|c|c|}
\hline Presenting symptom & $\begin{array}{c}\text { Total no of } \\
\text { patients }\end{array}$ & $\%$ \\
\hline menorrhagia & 72 & $36 \%$ \\
\hline menometrorhagia & 62 & $31 \%$ \\
\hline polymenorrhoea & 31 & $15.5 \%$ \\
\hline metrorhagia & 06 & $3 \%$ \\
\hline Postmenopausal bleeding & 25 & $12.5 \%$ \\
\hline oligomenorrhoea & 04 & $2 \%$ \\
\hline Total & 200 & \\
\hline
\end{tabular}

Menorrhagia was the most common presenting symptom in $72(36 \%)$ patients followed by menometrorhagia in $62(31 \%)$ patients. $31(15.5 \%)$ patients had polymenorrhagia as their chief complaint and $25(12.5 \%)$ had postmenopausal bleeding. $6(3 \%)$ and $4(2 \%)$ had metrorhagia and oligomenorrhoea as chief complaint respectively .

Table 3: Ultrasonography findings

\begin{tabular}{|l|c|c|}
\hline Sonography Finding & Total No & $\%$ \\
\hline Thickened endometrium & 82 & $41 \%$ \\
\hline Fibroid uterus & 42 & $21 \%$ \\
\hline Endometrial polyp & 30 & $15 \%$ \\
\hline Ovarian cyst /adenexal mass & 10 & $5 \%$ \\
\hline Thickened ET with cystic areas & 6 & $3 \%$ \\
\hline Bulky uterus & 12 & $6 \%$ \\
\hline Normal & 38 & $19 \%$ \\
\hline
\end{tabular}

Usg was normal in $38(19 \%)$ patients $81 \%$ were diagnosed to have uterine pathology on usg Out of that 20 patients had multiple pathology . $82(41 \%)$ patients had thickened endometrium reported on usg, $42(21 \%)$ had fibroids, $10(5 \%)$ patients had ovarian cyst or adenexal mass.

$30(15 \%)$ patients had endometrial polyp on usg, $12(6 \%)$ had bulky uterus, and $6(3 \%)$ had thick endometrial lining with cystic spaces in endometrium.

Thus intracavitary lesions on USG account for 118 cases ie almost $60 \%$.

Table 4: hysteroscopy findings

\begin{tabular}{|l|c|c|}
\hline Hysteroscopy Finding & Total & $\%$ \\
\hline Thickened hyperplastic endometrium & 72 & $36 \%$ \\
\hline Thickened polypoidal endometrium & 32 & $16 \%$ \\
\hline polyps & 82 & $41 \%$ \\
\hline Submucous fibroid & 6 & $3 \%$ \\
\hline adhesions & 5 & $2.5 \%$ \\
\hline Atrophic endometrial lining & 3 & $1.5 \%$ \\
\hline & 200 & \\
\hline
\end{tabular}

Most common finding on hysteroscopy was polyp in $114(57 \%)$ patients. 82(41\%) patients had normal endometrial lining with polyps while $32(16 \%)$ had thickened endometrium with polyp. Another 72 (36\%) had thickened hyperplastic endometrium on hysteroscopy

6 patients had submucous fibroid and 5 had intrauterine adhesions while 3 patients had atrophic lining.

Most of these patients with polyps had polypectomy done in same sitting along with endometrial biopsy, both samples were sent for histopathological examination in separate containers. patients with adhesions had hysteroscopic adhesiolysis done in same sitting.

Those with submucous fibroid less than $3 \mathrm{~cm}$ and totally in the cavity had removal of submucous fibroid while those with larger fibroids and partly intramural partly submucous type was not removed in same sitting. Those with thickened hyperplastic endometrium had hysteroscopic guided biopsy done

Biopsy of endometrium and intrauterine lesion was done in all cases .histopathology was evaluated for all patients 
Table 5: biopsy reports

\begin{tabular}{|l|c|c|}
\hline Biopsy report & Total & \\
\hline proliferative endometrium & 15 & $7.5 \%$ \\
\hline Secretary endometrium & 08 & $4 \%$ \\
\hline Simple cystic hyperplasia without atypia & 52 & $26 \%$ \\
\hline Simple cystic hyperplasia with atypia & 11 & $5.5 \%$ \\
\hline Complex hyperplasia without atypia & 02 & $1 \%$ \\
\hline Complex hyperplasia with atypia & 04 & $2 \%$ \\
\hline Benign endometrial polyp & 50 & $25 \%$ \\
\hline Benign endocervical polyp & 30 & $15 \%$ \\
\hline Leiomyomatous polyp & 16 & $8 \%$ \\
\hline Submucous leiomyoma & 06 & $3 \%$ \\
\hline Placental polyp & 01 & $0.5 \%$ \\
\hline Squamous cell ca in cervical polyp & 01 & $0.5 \%$ \\
\hline CIN in cervical polyp & 02 & $1 \%$ \\
\hline Adenocarcinoma & 04 & $2 \%$ \\
\hline Scanty endometrium & 12 & $6 \%$ \\
\hline
\end{tabular}

105 patients with polyps were removed hysteroscopically. out of that 50 had benign endometrial polyps, 30 had endocervical polyps, 16 had leiomyomatous polyp, 6 patients had small submucus myomas removed hysteroscopically and 1 case of placental polyp and 2 cases of cervical polyp which had CIN were removed.

12 cases had scanty endometrium on biopsy .out of that 7 patients had postmenopausal bleeding all of these patients had benign endometrial polyp with scanty endometrium .polyp removed with hysteroscopy hence they did not need any other treatment as they were relieved of symptoms after procedure and biopsy showed atrophic endometrium which is reassuring .

5 patients were in reproductive age group with oligomenorhoea and intrauterine adhesions on hysteroscopy they had adhesiolysis done.

15 patients had thickened endometrium on hysteroscopy but biopsy showed proliferative endometrium only and 5 patients had secretary endometrium with no other abnormality Remaining 3 patients with secretary endometrium had fibroids.

Thus 20 patients had no other pathology detected on hysteroscopy and hysteroscopic guided biopsy was normal .which was reassuring.

\section{Discussion}

Abnormal uterine bleeding is a common clinical presentation in gynaecology OPD. it amounts to $35 \%$ of gynae OPD visits and $25 \%$ of gynaecological surgeries and this incidence rises to $65 \%$ in peri and postmenopausal age ${ }^{(1)}$ This condition has enormous consequences with regard to social life, morbidity and clinical workload ${ }^{(2-4)}$.

Hysteroscopy as an outpatient procedure is an important method for diagnosis of $\mathrm{AUB}^{(5,6)}$. Although the major role of out-patient hysteroscopy in the management of AUB, is diagnostic, there is scope for simple operative procedures such as polypectomy, and targeted endometrial biopsy $^{(6)}$.

This technique has replaced the procedure of dilatation and curettage which is a blind technique with a high diagnostic failure rate ${ }^{(7,8)}$

Tissue biopsy performed under direct visualization with hysteroscopy can provide better diagnostic possibilities compared with random sampling where small lesion can be missed ${ }^{(8)}$.

In our study 200 patients of AUB were included with a mean age of $45 \mathrm{yrs}$ and a range of 25-65 yrs. In the study of Chaudhari KR et al. ${ }^{(9)} 98$ cases with AUB were studied. most of the patients in their study were in the age group of 51-60 years with an average age of 44.2 years. This is consistent with findings in Trajkovic's in which mean age of patients with AUB was $41.5+7.8$ years. ${ }^{(10)}$

The most common indication for hysteroscopy in our study was menorrhagia in $36 \%$ cases similar to that of Chaudhari $\mathrm{K} \mathrm{R}$ et $\mathrm{al}^{(9)}$ where menorrhagia was present in $38.2 \%$ patients

The most common cause of AUB in our study was endometrial polyp in $41 \%$ cases followed by endometrial hyperplasia in $36 \%$ cases contrary to that of chaudhari et al where endometrial hyperplasia was most common in $27.4 \%$ cases followed by polyps in $14.7 \%$ cases. ${ }^{(9)}$

Most of these patients with polyps had polypectomy done in same sitting along with endometrial biopsy 
Those with submucous fibroid less than $3 \mathrm{~cm}$ and totally in the cavity had removal of submucous fibroid while those with larger fibroids and partly intramural partly submucous type was not removed in same sitting. Those with thickened hyperplastic endometrium had hysteroscopic guided biopsy done

Following the results of hitopathology patients were than appropriately managed with either medical therapy, conservative surgery like endometrial ablation, myomectomy, polypectomy or definitive surgery ie hysterectmy.

Hence around $70 \%$ patients had benign pathology which was managed by hysteroscopy and did not need any further treatment while $30 \%$ had endometrial hyperplasia, or malignancy hence they were managed by hysterectomy .

So majority of patients of AUB can be managed by see and treat hysteroscopy which is a much simpler procedure than hysterectomy. thus is very effective for both diagnosis as well as management of intrauterine pathology causing AUB.

\section{Conclusion}

Hysteroscopy allows proper diagnosis or exclusion of intracavitary pathology as well as treatment of them in same sitting with proper tissue biopsy from the abnormal area.

Hence it is ideal for diagnostic evaluation and management of intracavitary lesions causing abnormal uterine bleeding

\section{References}

1. Luigi Man, Paulo Vercellini.role of TVS and outpatient diagnostic hysteroscopy in evaluation of AUB.clinics of Obstetrics and gynaecology.2014.Available at :http://endometriosis .org/.

2. Mencaglia L, Perino A, Hamou J. Hysteroscopy in perimennopausal and postmenopausal women with abnormal uterine bleeding. J Reprod Med 1987;32:577- 582.
3. Bradlow J, Coulter A, Brooks P. Patterns of referral. A study of referrals to outpatient clinics from general practitioners in the in the Oxford region. Oxford: Oxford Health Services Research Unit, 1992.

4. Brill A. What is the role of hysteroscopy in the management of abnormal uterine bleeding? Clinical Obstet Gynecol 1995;38:319-45

5. Fung T, Lam M, Wong S. A randomised placebo controlled trial of vaginal misoprostol for cervical priming before hysteroscopy in postmenopausal women. Int J Obstet Gynecol 2002;5:561-5.

6. Cameron $\mathrm{S}$, Walker $\mathrm{J}$, hambers $\mathrm{S}$. Comparison of Transvaginal ultrasound, saline infusion sonography and hysteroscopy to investigate postmenopausal bleeding and unscheduled bleeding on HRT. Aust NZ J Obstet Gynecol 2001;3:291-4

7. Epstein E, Ramirez A, Skoog L, Valentin L. Dilatation and curettage fails to detect most lesions in the uterine cavity in women with postmenopausal bleeding. Acta Obstet Gynecol 2001; 12:1131-6

8. Grimes D. Diagnostic dilatation and curettage of reappraisal. Am J Obstet Gynecol 1982;47:300-6

9. Chaudhari KR et al. Int J Reprod Contracept Obstet Gynecol. 2014 Sep;3(3):666-670

10. Sonja Pop Trajkovic. Role of hysteroscopy in evaluation of patients with AUB. Clinic for gynecology and obstetrics, clinic centre Serbia. Sci J Faculty Med. 2011;28 (3):177-81. 